Lifetime measurements of odd-parity high-excitation levels of Sn I by time-resolved laser spectroscopy

This article has been downloaded from IOPscience. Please scroll down to see the full text article.

2010 J. Phys. B: At. Mol. Opt. Phys. 43205005

(http://iopscience.iop.org/0953-4075/43/20/205005)

View the table of contents for this issue, or go to the journal homepage for more

Download details:

IP Address: 193.190.193.2

The article was downloaded on 07/10/2010 at 15:52

Please note that terms and conditions apply. 


\title{
Lifetime measurements of odd-parity high-excitation levels of Sn I by time-resolved laser spectroscopy
}

\author{
Wei Zhang ${ }^{1}$, Yanyan Feng ${ }^{1}$, Jiaxin $\mathrm{Xu}^{1}$, Patrick Palmeri ${ }^{2}$, \\ Pascal Quinet $^{2,3}$, Émile Biémont ${ }^{2,3}$ and Zhenwen Dai ${ }^{1,4}$ \\ ${ }^{1}$ College of Physics, Jilin University and Key Lab of Coherent Light, Atomic and Molecular \\ Spectroscopy, Ministry of Education, Changchun 130021, People's Republic of China \\ ${ }^{2}$ Astrophysique et Spectroscopie, Université de Mons-UMONS, B-7000 Mons, Belgium \\ ${ }^{3}$ IPNAS (Bât. B15), Université de Liège, Sart Tilman, B-4000 Liège, Belgium \\ ${ }^{4}$ The Institute of Atomic and Molecular Physics, Jilin University, Changchun 130021, \\ People's Republic of China \\ E-mail: dai@jlu.edu.cn
}

Received 14 May 2010, in final form 14 August 2010

Published 5 October 2010

Online at stacks.iop.org/JPhysB/43/205005

\begin{abstract}
Natural radiative lifetimes of 38 odd-parity highly excited levels in neutral tin in the energy range from 43682.737 to $56838.68 \mathrm{~cm}^{-1}$ have been measured by a time-resolved laser-induced fluorescence technique in an atomic beam produced by laser ablation on a solid tin sample. All the levels were excited from the metastable ${ }^{3} \mathrm{P}_{1,2}$ and ${ }^{1} \mathrm{D}_{2}$ levels in the ground configuration. The second and third harmonics of a dye laser were adopted as the tunable exciting source $(207-250 \mathrm{~nm})$. The lifetime results obtained in this paper are in the range from 4.6 to $292 \mathrm{~ns}$ and will be useful in extending the set of oscillator strengths available in Sn I.
\end{abstract}

\section{Introduction}

Neutral tin is the second heaviest carbon group element and its singly excited configurations consist of an excited electron outside of a $5 \mathrm{p}$-electron ionic core with two ionization limits: ${ }^{2} \mathrm{P}_{1 / 2}^{\circ}\left(59232.69 \mathrm{~cm}^{-1}\right)$ and ${ }^{2} \mathrm{P}_{3 / 2}^{\circ}\left(63484.18 \mathrm{~cm}^{-1}\right)$ [1]. Due to its rather simple structure, the energy levels of Sn I have been investigated by several authors [1-11]. However, the experimental determination of Sn I lifetimes has been limited to a few lowly lying odd-parity levels and to some even-parity levels. In particular, the lifetime values for highexcitation odd-parity levels in this atom are still extremely scarce. For this parity, most resonant lines lie in UV and vacuum UV regions where it is somewhat difficult to get an efficient exciting light source.

In the early works on odd-parity levels, only nine radiative lifetimes of the $5 \mathrm{p} 6 \mathrm{~s}^{1} \mathrm{P}^{\circ}{ }_{1}$ and ${ }^{3} \mathrm{P}_{0,1,2}^{\circ}$, $5 \mathrm{p} 5 \mathrm{~d}^{3} \mathrm{D}_{1,2,3}^{\circ}$ and ${ }^{3} \mathrm{~F}_{2,3}^{\circ}$ levels have been investigated using various techniques including the Hanle-effect method, beam-foil spectroscopy, the phase-shift approach and the Rozhdestvenskii hook method [12-18]. It is remarkable that, for these nine lifetimes, only the $5 \mathrm{p} 5 \mathrm{~d}^{3} \mathrm{~F}_{2}^{\circ}$ lifetime reaches $24 \mathrm{~ns}$ while all the others are shorter than $7 \mathrm{~ns}$.

Recently, Xu et al [19] reported lifetimes for five oddparity levels $\left(5 \mathrm{p} 7 \mathrm{~s}^{3} \mathrm{P}^{\circ}{ }_{1}, 5 \mathrm{p} 5 \mathrm{~d}^{1} \mathrm{P}^{\circ}{ }_{1}, 5 \mathrm{p} 6 \mathrm{~d}^{3} \mathrm{~F}^{\circ}{ }_{2},{ }^{3} \mathrm{D}^{\circ}{ }_{1}\right.$ and $\left.{ }^{3} \mathrm{D}^{\circ}{ }_{3}\right)$ using the laser-induced fluorescence (LIF) technique. The lifetimes of nine even levels from the $5 p 7 p$ configuration have also been reported recently by Zhang et al [20]. In addition, 40 lifetimes belonging to the $5 \mathrm{p} n \mathrm{p} J=1(n=10-13,15-19)$ and $J=2(n=10-13,15-19,27,31,32), 5 p n f J=2(n=4$, $5,9-19,22,23)$ levels along Rydberg series and all the 5p8p perturbing levels are due to Zhang et al [21]. To the best of our knowledge, however, no additional recent work on lifetime determination in $\mathrm{Sn} \mathrm{I}$ is available in the literature.

Radiative data in Sn I are needed in many fields of physics. In atomic physics, atomic parameters, such as natural radiative lifetimes, Landé $g_{J}$ factors as well as hyperfine structure data are required in order to gain more insight into the properties of excited states of Sn I. In astrophysics, tin has been identified in the solar photospheric spectrum and in the spectra of some chemically peculiar hot stars [22], and it is well known that the determination of the chemical composition of the stars 


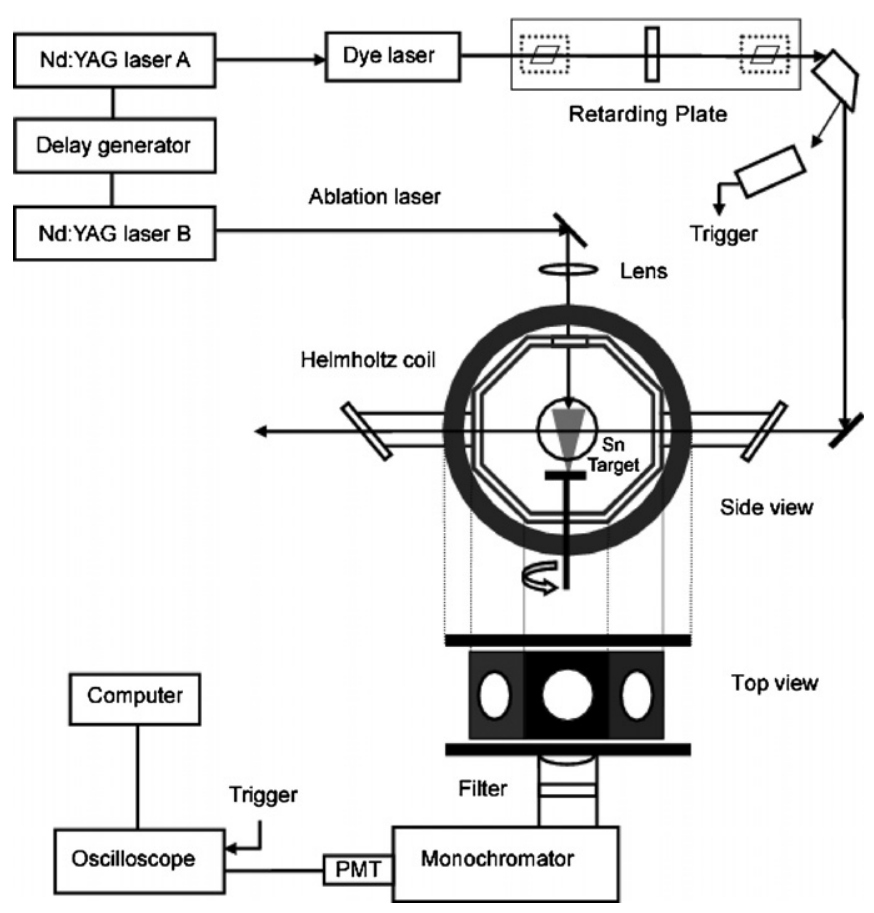

Figure 1. Experimental setup used for lifetime measurements.

is limited by the accuracy of the available atomic transition probabilities [23]. These last ones can be deduced from accurate radiative lifetimes and precise branching fractions obtained experimentally or theoretically. In laser physics, with the increasing demand for new or improved lasers and optical devices, many efforts have been devoted to the investigation of the radiative properties of atomic highly lying states (including those of tin ions), which appear as efficient sources of pulsed radiation in selected spectral regions. Recently, in order to control the environmental pollution, the use of tin, which is regarded as an innocuous substitute for lead, has appeared as an imperative alternative [24].

For all the above reasons, more insight into the physical properties of Sn I, particularly the measurement of new lifetimes in this atom, is justified and timely. In this paper, we report on the lifetime measurements of 38 odd-parity Rydberg levels of Sn I using a time-resolved laser-induced fluorescence technique in an atomic beam of laser-produced plasma.

\section{Experimental setup}

The experimental setup used here for lifetime measurements is shown in figure 1. Since most of the odd-parity levels investigated in this paper are located in the VUV region but a VUV laser is not currently available in our laboratory, the levels measured here were excited from the metastable levels ${ }^{3} \mathrm{P}_{1,2}$ and ${ }^{1} \mathrm{D}_{2}$ at $1691.806,3427.673$ or $8612.955 \mathrm{~cm}^{-1}$, respectively. In order to produce a sufficient density of atoms in the metastable states, a laser-produced plasma obtained through laser ablation on a tin sample with a purity of $99.8 \%$ has been employed as an atomic source. This technique has appeared previously to be very efficient and reliable for lifetime measurements [25, 26]. A $5 \mathrm{~mJ} 532 \mathrm{~nm}$ pulse, with about 8 ns duration, emitted by a Q-switched Nd:YAG laser (Continuum Precision II) working at a $10 \mathrm{~Hz}$ repetition rate, was focused on a thin target plate, which was fixed on a small rotating platform driven by an electromotor. The rotation speed of the platform was appropriate to ensure an ablation position different for each laser pulse. A linearly polarized dye laser (Sirah Cobra-Stretch), operating with Coumarin 440, 460, 480 and DCM dyes, respectively, which was pumped by a Q-switched Nd:YAG 355 nm laser (Spectra-Physics QuantaRay Pro-Series) working at $10 \mathrm{~Hz}$ with about $8 \mathrm{~ns}$ pulse duration, was used for the excitation. The linewidth of the dye laser was about $0.08 \mathrm{~cm}^{-1}$. In order to obtain the tunable UV radiation from 205 to $250 \mathrm{~nm}$, the frequency doubling and tripling of the fundamental frequency have been used. The second harmonic of a dye laser was produced through a BBO type-I crystal, while the third harmonic was generated by mixing the second harmonic with the remaining fundamental frequency in another BBO type-I crystal following a retarding plate. This one was used to make the polarization directions of the second harmonic and the fundamental frequency lasers parallel. Then, the light emitted by the excitation laser with about 5-7 ns pulse duration was sent horizontally through the vacuum chamber, where it intersected the vertical atomic beam about $10 \mathrm{~mm}$ above the target. The interval between the excitation and ablation pulses could be arbitrarily adjusted by a digital delay generator (Stanford Research Systems Model 535). Following the excitation, the fluorescence signal was focused into a grating monochromator by a convex silica lens in a direction perpendicular to the laser and the atomic beam, and then it was detected by a photomultiplier tube (PMT) (Hamamatsu R3896). In experiments, the monochromator was placed by rotating it $90^{\circ}$, so that its entrance slit was horizontal and parallel to the excitation beam to enhance the fluorescence collection efficiency. In order to avoid the flight-out-of-view effect, the slit was opened to the farthest point (about $5 \mathrm{~mm}$ ), and accordingly the spectral width of the monochromator was also very large (about $25 \mathrm{~nm}$ ). In this case, a spectral filter, which cut the light with a wavelength longer than $300 \mathrm{~nm}$, was used between the lens and the monochromator to prevent the cascade fluorescence at about $320 \mathrm{~nm}$ from lower levels to reach the PMT. Since the levels are selectively excited by the laser, there are no cascade emissions from higher excitation levels [27]. A $500 \mathrm{MHz}$ digital oscilloscope (Tektronix TDS 620B), triggered by the excitation laser with a fast photoelectric diode, was used to register the time-resolved fluorescence photocurrent signal from the PMT. The oscilloscope was connected through a GPIB cable to a computer in which the signal data could be stored and analysed.

In the direction parallel to the horizontal component of the Earth's magnetic field, an appropriate magnetic field produced by a pair of Helmholtz coils was used to wash out the possible distortion of the decay signal induced by both the recombination background [28] and the quantum beats produced by the Earth's magnetic field [29]. 


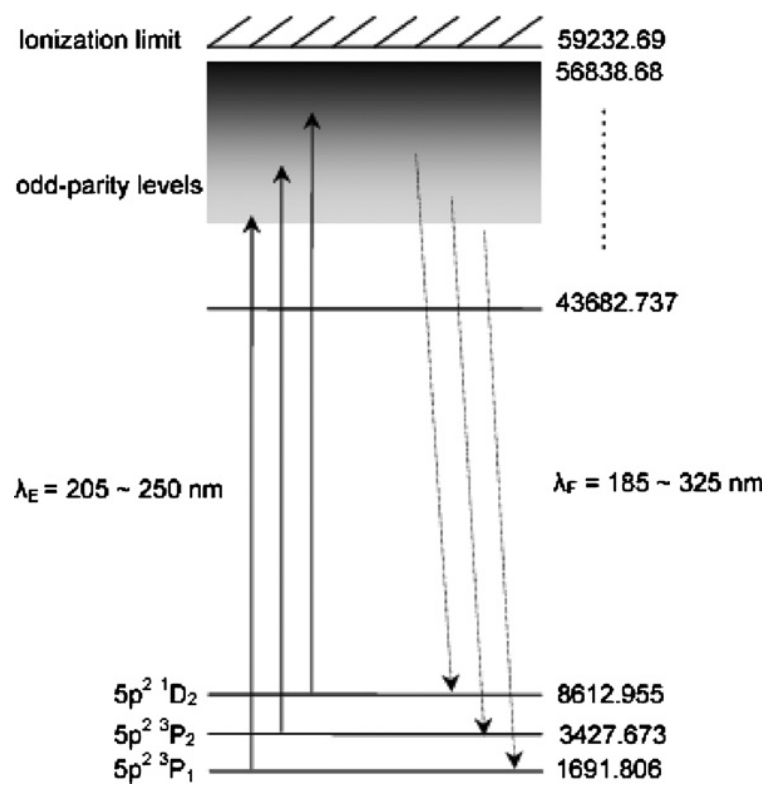

Figure 2. Partial energy-level diagram of Sn I and excitation schemes. The solid lines indicate the excitation pathways, and the dashed lines show the fluorescence channels. All energies are expressed in $\mathrm{cm}^{-1}$.

\section{Measurements}

The diagram of the energy levels and the detailed excitation schemes relevant to the experiment are illustrated in figure 2. In the measurements, the excitation of a selected level could be confirmed by checking the disappearance of the signal when blocking the ablation laser and by verifying that the fluorescence channels were effectively related to this level.

In the experiment, the recombination background could be eliminated by applying an appropriate magnetic field when the fluorescence signals were recorded with a sufficiently long delay after the excitation pulse. In this work, all the measurements were performed at a typical magnetic field of $100 \mathrm{G}$, sufficient to wash out a possible distortion in the decay signal. With delays between 10 and $75 \mu \mathrm{s}$, the intensities of the detected fluorescence signals were changed by a factor ranging from 5 to 10 , and it was verified that the evaluated lifetimes remained constant within the experimental errors. In this process, the speed of the atoms and the density in the excitation region gradually decreased and hence the possible effects of flight-out-of-view, radiation trapping, super-radiation, PMT nonlinear response and collision-induced quenching may be effectively checked and eventually eliminated. In addition, possible collision with remnant gas was checked by changing the pressure in the vacuum chamber from $2 \times 10^{-4}$ to $3 \times 10^{-3}$ $\mathrm{Pa}$, while the flight-out-of-view effects were considered again by changing the width and the position of the monochromator slit. In addition, through the modification of the pulse energies of the ablation and excitation lasers, the effects of radiation trapping, nonlinear response of the PMT detector and superradiation have been analysed and eliminated when the delay between the excitation and ablation pulses was appropriate. Finally, the blackbody radiation (BBR) effect [30] could be considered as negligible in the present work since each

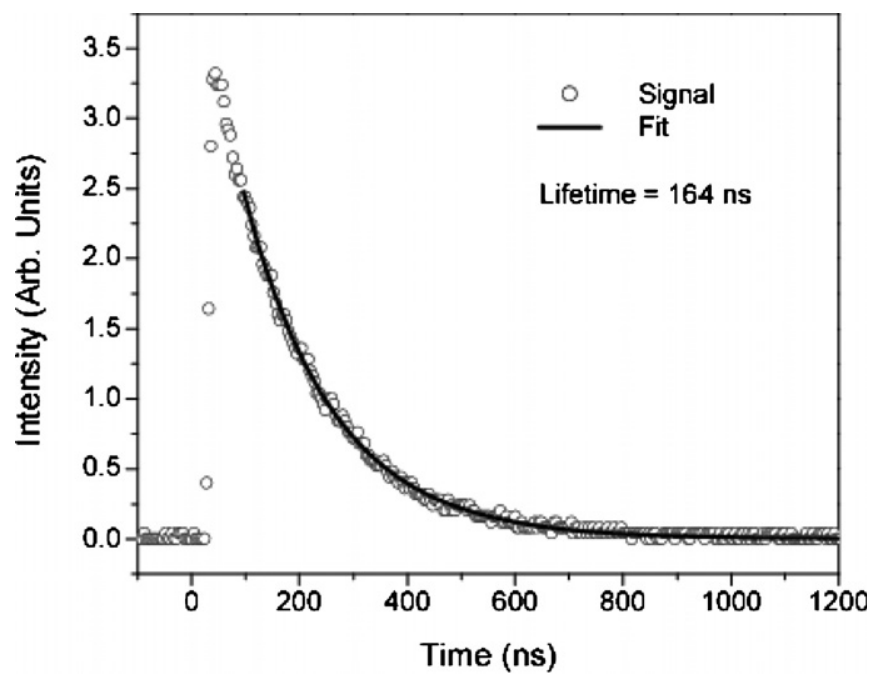

Figure 3. Typical fluorescence decay curve of the $5 \mathrm{p} 8 \mathrm{~d}^{3} \mathrm{~F}_{2}^{\circ}$ level with an exponential fitting for lifetime evaluation.

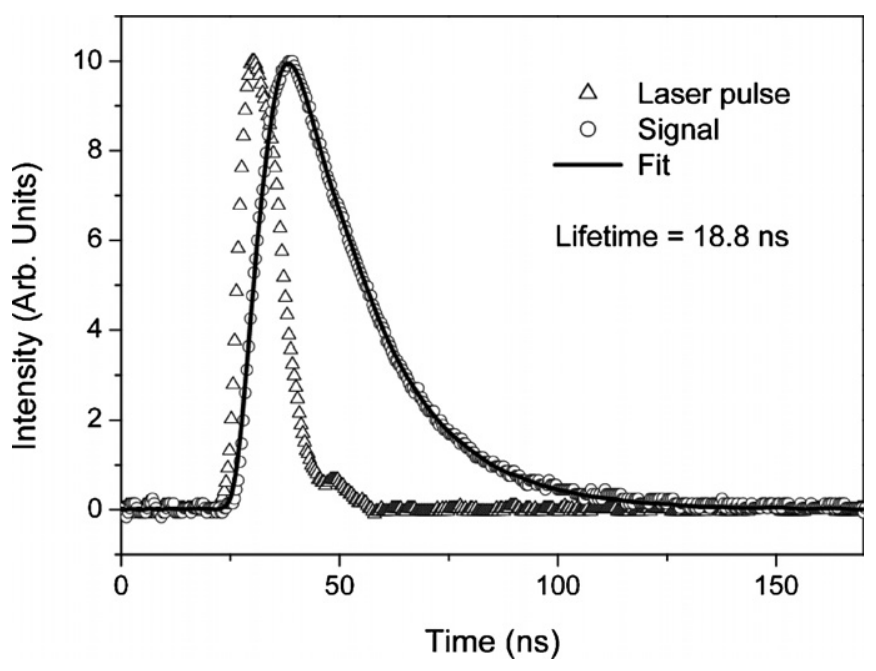

Figure 4. Fluorescence decay curve of the $5 \mathrm{p} 8 \mathrm{~s}^{3} \mathrm{P}^{\circ}{ }_{1}$ level together with the fitted convolution curve between the laser pulse and an exponential with a decay constant of $18.8 \mathrm{~ns}$.

investigated level had not only large energy spacing with respect to the adjacent levels accessible by a dipolar transition but also a much shorter lifetime compared with the BBR relaxation time.

For improving the signal, more than 1000 shots were averaged for each fluorescence decay curve. For a level with a lifetime longer than $70 \mathrm{~ns}$, which corresponds to ten times the excitation pulse duration, the lifetime value may be evaluated by a least-squares exponential fitting to the recorded fluorescence curves. However, we had to be cautious when choosing the starting point of the fitting procedure in order to avoid the stray light of the exciting laser. A typical fluorescence decay curve of the $5{\mathrm{p} 8 \mathrm{~d}^{3} \mathrm{~F}^{\circ}}_{2}$ level with an exponential fitting for lifetime evaluation is shown in figure 3. For the levels with shorter lifetimes, a deconvolution of the fluorescence decay curves is necessary to obtain the true lifetime of the levels [31]. In this case, the exciting laser pulse, which corresponds to the product of the real intensity of the 
Table 1. Measured lifetimes for odd-parity levels in the $5 \mathrm{p} n \mathrm{~d}, 5 \mathrm{p} n \mathrm{~s}$ and $5 \mathrm{~s} 5 \mathrm{p}^{3}$ configurations of Sn I and comparison with previous results. The excitation (Exc.) and fluorescence (Obs.) wavelengths are also given.

\begin{tabular}{|c|c|c|c|c|c|c|}
\hline \multirow[b]{2}{*}{ Config. } & \multirow[b]{2}{*}{ Term } & \multirow[b]{2}{*}{ Level $\left(\mathrm{cm}^{-1}\right)$} & \multirow[b]{2}{*}{ Exc. (nm) } & \multirow[b]{2}{*}{ Obs. (nm) } & \multicolumn{2}{|r|}{ Lifetime (ns) } \\
\hline & & & & & This work & Previous \\
\hline $5 \mathrm{p} 5 \mathrm{~d}^{\mathrm{a}, \mathrm{d}, \mathrm{h}}$ & ${ }^{1} \mathrm{D}_{2}^{\circ}{ }^{\mathrm{a},},{ }^{3} \mathrm{~F}_{2}^{\circ}{ }_{2}^{\mathrm{c}, \mathrm{d}, \mathrm{h}}$ & $43682.737^{\mathrm{a}}$ & 238.147 & 285.1 & $23(2)$ & $24(2)^{\mathrm{h}}$ \\
\hline $5 \mathrm{p} 5 \mathrm{~d}^{\mathrm{a}, \mathrm{d}, \mathrm{f}, \mathrm{h}}$ & ${ }^{3} \mathrm{D}_{2}^{\circ}{ }^{\mathrm{a}, \mathrm{c}, \mathrm{d}, \mathrm{f}, \mathrm{h}}$ & $44144.368^{\mathrm{a}}$ & 235.557 & 281.4 & $5.7(7)$ & $5.1^{\mathrm{e}}, 5.5(4)^{\mathrm{f}}, 6.8(7)^{\mathrm{h}}$ \\
\hline $5 \mathrm{p} 5 \mathrm{~d}^{\mathrm{a}, \mathrm{d}, \mathrm{f}, \mathrm{g}, \mathrm{h}}$ & ${ }^{3} \mathrm{D}^{\circ}{ }_{1}^{\mathrm{a}, \mathrm{c}, \mathrm{d}, \mathrm{f}, \mathrm{g}, \mathrm{h}}$ & $44508.677^{\mathrm{a}}$ & 243.421 & 278.6 & $4.6(3)$ & $3.9^{\mathrm{e}}, 3.9(5)^{\mathrm{f}}, 4.5(5)^{\mathrm{f}}, 4.5 \pm 0.5^{\mathrm{g}}, 5.5 \pm 0.6^{\mathrm{h}}$ \\
\hline $5 \mathrm{p} 5 \mathrm{~d}^{\mathrm{a}, \mathrm{d}, \mathrm{f}, \mathrm{h}}$ & 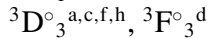 & $44576.006^{\mathrm{a}}$ & 243.023 & 278.1 & $7.3(3)$ & $5.0^{\mathrm{e}}, 5.8(6)^{\mathrm{f}}, 6.9(7)^{\mathrm{h}}$ \\
\hline $5 \mathrm{p} 5 \mathrm{~d}^{\mathrm{a}, \mathrm{d}}$ & ${ }^{3} \mathrm{~F}_{2}^{\circ}{ }^{\mathrm{a}},{ }^{1} \mathrm{D}_{2}^{\circ}{ }_{2}^{\mathrm{c}, \mathrm{d}}$ & $47145.684^{\mathrm{a}}$ & 228.739 & 259.5 & $13.2(9)$ & \\
\hline $5 \mathrm{p} 5 \mathrm{~d}^{\mathrm{a}, \mathrm{d}, \mathrm{g}, \mathrm{h}}$ & ${ }^{3} \mathrm{~F}_{3}^{\circ} \mathrm{a}, \mathrm{c}, \mathrm{h},{ }^{3} \mathrm{D}_{3}^{\circ} \mathrm{d}, \mathrm{g}$ & $47487.696^{\mathrm{a}}$ & 226.948 & 257.2 & $7.4(5)$ & $6.0(6)^{\mathrm{h}}, 6.5(1.0)^{\mathrm{g}}$ \\
\hline $5 \mathrm{p} 7 \mathrm{~s}^{\mathrm{c}, \mathrm{d}}$ & ${ }^{3} \mathrm{P}_{0}^{\circ} \mathrm{c}, \mathrm{d}$ & $48216.36^{\mathrm{b}}$ & 214.950 & 214.9 & 21.3(9) & \\
\hline $5 \mathrm{p} 7 \mathrm{~s}$ & ${ }^{3} \mathrm{P}_{1}^{\circ}{ }_{1}^{\mathrm{c}, \mathrm{d}}$ & $48222.16^{\mathrm{b}}$ & 223.242 & 252.5 & $20.4(6)$ & $61(2)^{\mathrm{i}}$ \\
\hline $5 \mathrm{p} 5 \mathrm{~d}^{\mathrm{a}, \mathrm{c}, \mathrm{d}}$ & ${ }^{3} \mathrm{P}_{2}^{\circ}{ }^{\mathrm{a}, \mathrm{c}, \mathrm{d}}$ & $48669.409^{a}$ & 221.035 & 198.4 & $6.7(3)$ & \\
\hline $5 \mathrm{p} 5 \mathrm{~d}^{\mathrm{a}, \mathrm{c}, \mathrm{d}}$ & ${ }^{3} \mathrm{P}_{1}^{\circ}{ }_{1}^{\mathrm{a}, \mathrm{c}, \mathrm{d}}$ & $48981.934^{\mathrm{a}}$ & 219.518 & 247.7 & $5.7(4)$ & \\
\hline $5 \mathrm{p} 5 \mathrm{~d}^{\mathrm{a}, \mathrm{c}, \mathrm{d}}$ & ${ }^{3} \mathrm{P}_{0}^{\circ}{ }^{\mathrm{a}, \mathrm{b}, \mathrm{c}, \mathrm{d}}$ & $49487.127^{\mathrm{a}}$ & 209.226 & 209.2 & $6.8(4)$ & \\
\hline $5 \mathrm{p} 5 \mathrm{~d}^{\mathrm{a}, \mathrm{d}}$ & ${ }^{1} \mathrm{~F}_{3}^{\circ}{ }^{\mathrm{a}, \mathrm{d}}$ & $49893.823^{\mathrm{a}}$ & 242.243 & 242.2 & $5.3(4)$ & \\
\hline $5 \mathrm{p} 5 \mathrm{~d}^{\mathrm{a}, \mathrm{c}, \mathrm{d}}$ & ${ }^{1} \mathrm{P}_{1}^{\circ}{ }_{1}^{\mathrm{a}, \mathrm{c}, \mathrm{d}}$ & $50125.971^{\mathrm{a}}$ & 240.889 & 303.4 & $11.3(4)$ & $8.8(6)^{i}$ \\
\hline $5 \mathrm{p} 6 \mathrm{~d}^{\mathrm{c}, \mathrm{d}}$ & ${ }^{3} \mathrm{D}^{\circ}{ }_{2}^{\mathrm{c}, \mathrm{d}}$ & $51010.94^{\mathrm{b}}$ & 235.860 & 202.8 & $28(3)$ & \\
\hline $5 p 6 d^{c, d}$ & ${ }^{3} \mathrm{~F}^{\circ}{ }_{2}^{\mathrm{c}, \mathrm{d}}$ & $51160.52^{b}$ & 209.499 & 209.5 & $45(4)$ & $89(5)^{\mathrm{i}}$ \\
\hline $5 p 6 d^{c, d}$ & ${ }^{3} \mathrm{D}^{\circ}{ }_{1}^{\mathrm{c}, \mathrm{d}}$ & $51474.74^{b}$ & 233.308 & 291.4 & $16.3(5)$ & $49(8)^{i}$ \\
\hline $5 p 6 d^{c, d}$ & ${ }^{3} \mathrm{D}_{3}^{\circ}{ }^{\mathrm{c}},{ }^{3} \mathrm{~F}_{3}^{\circ}{ }^{\mathrm{d}}$ & $51754.67^{b}$ & 231.794 & 206.9 & $6.6(3)$ & $61(4)^{\mathrm{i}}$ \\
\hline $5 \mathrm{p} 7 \mathrm{~s}$ b,c,d & ${ }^{3} \mathrm{P}_{2}^{\circ} \mathrm{b,c,d}$ & $52415.83^{b}$ & 228.296 & 197.1 & $14.4(5)$ & \\
\hline $5 \mathrm{p} 7 \mathrm{~s}^{\mathrm{c}, \mathrm{d}}$ & ${ }^{1} \mathrm{P}^{\circ}{ }_{1}^{\mathrm{c}, \mathrm{d}}$ & $52706.80^{\mathrm{b}}$ & 226.78 & 281.4 & $14.6(3)$ & \\
\hline $5 \mathrm{p} 8 \mathrm{~s}^{\mathrm{c}, \mathrm{d}}$ & ${ }^{3} \mathrm{P}_{1}^{\circ}{ }_{1}^{\mathrm{c}, \mathrm{d}}$ & $53020.97^{b}$ & 225.186 & 188.6 & $18.8(4)$ & \\
\hline $5 s 5 p^{3 b, d}$ & ${ }^{3} \mathrm{D}_{2}^{\circ}{ }_{2}^{\mathrm{b}, \mathrm{c}, \mathrm{d}}$ & $53631.83^{b}$ & 222.131 & 192.5 & $25(2)$ & \\
\hline $5 s 5 p^{3 b, d}$ & ${ }^{3} \mathrm{D}_{3}^{\circ}{ }_{3}^{\mathrm{b}, \mathrm{c}, \mathrm{d}}$ & $53826.55^{b}$ & 221.172 & 198.4 & $32(3)$ & \\
\hline $5 p 7 d^{c, d}$ & ${ }^{3} \mathrm{~F}_{2}^{\circ}{ }^{\mathrm{c}, \mathrm{d}}$ & $54211.76^{b}$ & 219.304 & 196.3 & $146(5)$ & \\
\hline $5 p 7 d^{d}$ & ${ }^{3} \mathrm{P}^{\circ}{ }_{2}{ }^{\mathrm{c}},{ }^{3} \mathrm{~F}_{3}^{\circ}{ }^{\mathrm{d}}$ & $54653.86^{\mathrm{b}}$ & 217.196 & 195.2 & $42(2)$ & \\
\hline $5 p 6 d^{d}$ & ${ }^{1} \mathrm{D}_{2}^{\circ}{ }^{\mathrm{d}}$ & $54713.32^{b}$ & 216.920 & 216.9 & $133(4)$ & \\
\hline $5 \mathrm{p} 7 \mathrm{~d}^{\mathrm{d}}$ & ${ }^{3} \mathrm{D}^{\circ}{ }_{1}^{\mathrm{c}, \mathrm{d}}$ & $55073.21^{\mathrm{b}}$ & 215.234 & 215.2 & 292(9) & \\
\hline $5 p 9 s^{d}$ & ${ }^{3} \mathrm{P}_{0}^{\circ}{ }_{0}^{\mathrm{d}}$ & $55131.53^{b}$ & 214.971 & 193.4 & 17.1(9) & \\
\hline $5 p 9 s^{c, d}$ & ${ }^{3} \mathrm{P}_{1}^{\circ} \mathrm{c}, \mathrm{d}$ & $55156.74^{b}$ & 214.855 & 193.3 & $33(2)$ & \\
\hline $5 p 6 d^{c, d}$ & ${ }^{1} \mathrm{D}_{2}^{\circ}{ }_{2}^{\mathrm{c}},{ }^{3} \mathrm{P}_{2}^{\circ}{ }^{\mathrm{d}}$ & $55296.28^{b}$ & 214.209 & 186.6 & $29(2)$ & \\
\hline $5 p 6 d^{d}$ & ${ }^{3} \mathrm{P}_{1}^{\circ}{ }_{1}^{\mathrm{d}}$ & $55688.37^{\mathrm{b}}$ & 212.425 & 191.3 & $31(3)$ & \\
\hline $5 p 8 d^{d}$ & ${ }^{3} \mathrm{~F}_{3}^{\circ}{ }_{3}^{\mathrm{c}, \mathrm{d}}$ & $55741.17^{b}$ & 212.187 & 191.2 & $39(2)$ & \\
\hline $5 \mathrm{p} 8 \mathrm{~d}^{\mathrm{c}, \mathrm{d}}$ & ${ }^{3} \mathrm{~F}^{\circ}{ }_{2}{ }^{\mathrm{c}},{ }^{3} \mathrm{P}_{2}^{\circ}{ }^{\mathrm{d}}$ & $55805.35^{b}$ & 211.908 & 211.9 & $48(3)$ & \\
\hline $5 p 8 d^{d}$ & ${ }^{3} \mathrm{~F}_{2}^{\circ}{ }^{\mathrm{d}}$ & $55854.62^{b}$ & 211.678 & 190.7 & $164(6)$ & \\
\hline $5 p 8 d^{d}$ & ${ }^{3} \mathrm{D}^{\circ}{ }_{1}^{\mathrm{d}}$ & $56242.35^{\mathrm{b}}$ & 209.954 & 189.3 & $34(3)$ & \\
\hline $5 \mathrm{p} 6 \mathrm{~d}^{\mathrm{c}, \mathrm{d}}$ & ${ }^{1} \mathrm{~F}_{3}^{\circ}{ }^{\mathrm{c}, \mathrm{d}}$ & $56297.98^{b}$ & 209.709 & 209.7 & $11.8(5)$ & \\
\hline $5 \mathrm{p} 10 \mathrm{~s}^{\mathrm{c}, \mathrm{d}}$ & ${ }^{3} \mathrm{P}_{1}^{\circ}{ }_{1}^{\mathrm{c}, \mathrm{d}}$ & $56390.11^{b}$ & 209.309 & 254.5 & $45(3)$ & \\
\hline $5 p 6 d^{d}$ & ${ }^{1} \mathrm{P}^{\circ}{ }_{1}^{\mathrm{d}}$ & $56659.18^{\mathrm{b}}$ & 208.133 & 253.2 & $16.7(7)$ & \\
\hline $5 p 9 d^{d}$ & ${ }^{3} \mathrm{~F}_{3}^{\circ} \mathrm{d}$ & $56838.68^{b}$ & 207.358 & 187.2 & $16.1(2)$ & \\
\hline
\end{tabular}

a Sansonetti and Martin [11].

b Brown et al [1].

c Moore [2].

d Dembczynski and Rebel [9].

e Penkin and Slavenas [12].

${ }^{\mathrm{f}}$ Holmgren and Svanberg [16].

g Andersen et al [17].

${ }^{\mathrm{h}}$ Gorshkov and Verolainen [18].

i Xu et al [19].

laser pulse and the instrumental response function, needs to be recorded by the same detection system. A typical fluorescence decay curve of the $5 \mathrm{p} 7 \mathrm{~s}^{3} \mathrm{P}^{\circ}{ }_{1}$ level, together with the fitted convolution curve of the laser pulse and an exponential with a decay lifetime of $18.8 \mathrm{~ns}$, is shown in figure 4.

In least-squares exponential fittings, for each fluorescence curve two lifetime values were determined with two starting points, respectively, one of which was chosen at a position outside the affected region of the stray light of exciting laser meanwhile with the strongest intensity and the other was at the position with a half intensity of the former point. In convolution fittings also two lifetime values were evaluated using two exciting pulses recorded, respectively, before and after the register of the corresponding fluorescence signal. The two lifetimes from one curve have a little difference, which are mainly due to some systematic effects on both fluorescence curves and exciting pulse shapes including the transit time jitter of the PMT (1.2 ns), the intensity nonlinear response of the whole detection system, the randomicity of the stray light of exciting laser when registering exciting pulses, etc. The mean value of the two lifetimes and its standard deviation were taken to be the radiative lifetime revealed by the curve and its 
Table 2. Evaluated lifetimes of some 5p5d, 5p6d and 5p7s levels and comparison with experimental results.

\begin{tabular}{|c|c|c|c|c|c|c|}
\hline \multirow[b]{2}{*}{ Config. and term } & \multirow[b]{2}{*}{ Level $\left(\mathrm{cm}^{-1}\right)$} & \multirow[b]{2}{*}{$n^{*}$} & \multicolumn{4}{|c|}{ Lifetime (ns) } \\
\hline & & & Previous & Evaluated by $\left(n^{*}\right)^{3}$ & This work & $\mathrm{Xu}$ et al [19] \\
\hline \multicolumn{7}{|c|}{$J=1$} \\
\hline $5 p 6 s^{3} \mathrm{P}_{1}^{\circ}$ & 34914.282 & 2.12 & $4.75(18)^{\mathrm{a}}$ & & & \\
\hline $5 \mathrm{p} 7 \mathrm{~s}^{3} \mathrm{P}_{1}^{\circ}$ & 48222.16 & 3.16 & & 15.7 & $20.4(6)$ & $61(2)$ \\
\hline $5 \mathrm{p} 6 \mathrm{~s}^{1} \mathrm{P}_{1}^{\circ}$ & 39257.053 & 2.34 & $4.11(22)^{\mathrm{a}}$ & & & \\
\hline $5 \mathrm{p} 7 \mathrm{~s}^{1} \mathrm{P}_{1}^{\circ}$ & 52706.80 & 4.01 & & 20.7 & $14.6(3)$ & \\
\hline $5 \mathrm{p} 5 \mathrm{~d}^{3} \mathrm{D}_{1}^{\circ}$ & 44508.677 & 2.73 & $4.5 \pm 0.5^{\mathrm{b}}$ & & $4.6(3)$ & \\
\hline $5 \mathrm{p} 5 \mathrm{~d}^{3} \mathrm{P}_{1}^{\circ}$ & 48981.934 & 3.27 & & 7.7 & $5.7(4)$ & \\
\hline $5 \mathrm{p} 5 \mathrm{~d}^{1} \mathrm{P}_{1}^{\circ}$ & 50125.971 & 3.47 & & 9.2 & $11.3(4)$ & $8.8(6)$ \\
\hline $5 p 6 d^{3} D_{1}^{\circ}$ & 51474.74 & 3.76 & & 11.8 & $16.3(5)$ & $49(8)$ \\
\hline \multicolumn{7}{|c|}{$J=2$} \\
\hline $5 \mathrm{p} 5 \mathrm{~d}^{1} \mathrm{D}^{\circ}{ }_{2},{ }^{3} \mathrm{~F}^{\circ}{ }_{2}$ & 43682.737 & 2.66 & $24 \pm 2^{\mathrm{c}}$ & & $23(2)$ & \\
\hline $5 \mathrm{p} 5 \mathrm{~d}^{3} \mathrm{~F}^{\circ}{ }_{2},{ }^{1} \mathrm{D}_{2}^{\circ}$ & 47145.684 & 3.01 & & 34.8 & $13.2(9)$ & \\
\hline $5 \mathrm{p} 6 \mathrm{~d}^{3} \mathrm{~F}_{2}^{\circ}$ & 51160.52 & 3.69 & & 64.1 & $45(4)$ & 89.4 \\
\hline \multicolumn{7}{|c|}{$J=3$} \\
\hline $5 \mathrm{p} 5 \mathrm{~d}^{3} \mathrm{D}^{\circ}{ }_{3},{ }^{3} \mathrm{~F}_{3}^{\circ}$ & 44576.006 & 2.74 & $5.8(6)^{\mathrm{a}}$ & & $7.3(3)$ & \\
\hline $5 \mathrm{p} 5 \mathrm{~d}^{3} \mathrm{~F}^{\circ}{ }_{3},{ }^{3} \mathrm{D}^{\circ}{ }_{3}$ & 47487.696 & 3.06 & $6.5 \pm 1^{\mathrm{c}}$ & 8.1 & $7.4(5)$ & \\
\hline $5 \mathrm{p} 5 \mathrm{~d}^{1} \mathrm{~F}^{\circ}{ }_{3}$ & 49893.823 & 3.43 & & $\begin{array}{r}0.1 \\
11.4\end{array}$ & $5.3(4)$ & \\
\hline $5 \mathrm{p} \mathrm{d}^{3} \mathrm{D}^{\circ}{ }_{3},{ }^{3} \mathrm{~F}^{\circ}{ }_{3}$ & 51754.67 & 3.83 & & 15.8 & $6.6(3)$ & 61.3 \\
\hline
\end{tabular}

${ }^{a}$ Holmgren and Svanberg [16].

${ }^{\mathrm{b}}$ Andersen et al [17].

${ }^{\mathrm{c}}$ Gorshkov and Verolainen [18].

systematic error, respectively. For each level, 30-50 curves were recorded under different experimental conditions, and the lifetimes and the systematic errors, evaluated from the curves recorded after a sufficiently long delay from the ablation pulse through above-mentioned method, were averaged to obtain the final lifetime and systematic error results, respectively.

\section{Results and discussion}

The lifetimes of the $5 \mathrm{p} 5 \mathrm{~d}^{1} \mathrm{D}^{\circ}{ }_{2},{ }^{3} \mathrm{D}^{\circ}{ }_{1,2,3},{ }^{3} \mathrm{~F}_{2,3}^{\circ},{ }^{3} \mathrm{P}^{\circ}{ }_{1,2,3},{ }^{1} \mathrm{~F}_{3}^{\circ}$, ${ }^{1} \mathrm{P}_{1}^{\circ}, 5 \mathrm{p} 6 \mathrm{~d}^{3} \mathrm{D}^{\circ}{ }_{1,2,3},{ }^{3} \mathrm{~F}_{2}^{\circ}, 5 \mathrm{p} 6 \mathrm{~d}^{3} \mathrm{P}^{\circ}{ }_{2},{ }^{3} \mathrm{D}^{\circ}{ }_{1},{ }^{1} \mathrm{D}_{2}^{\circ},{ }^{3} \mathrm{~F}^{\circ}{ }_{3},{ }^{1} \mathrm{P}^{\circ}{ }_{1}$, ${ }^{1} \mathrm{~F}_{3}^{\circ}, 5 \mathrm{p} 7 \mathrm{~d}^{3} \mathrm{D}_{2,3}^{\circ},{ }^{3} \mathrm{~F}_{2,3}^{\circ}, 5 \mathrm{p} 8 \mathrm{~d}^{3} \mathrm{D}^{\circ}{ }_{1,2},{ }^{3} \mathrm{~F}_{2}^{\circ}, 5 \mathrm{p} 7 \mathrm{~s}^{3} \mathrm{P}_{0,1,2}^{\circ}$, ${ }^{1} \mathrm{P}^{\circ}{ }_{1}, 5 \mathrm{p} 9 \mathrm{~s}^{3} \mathrm{P}^{\circ}{ }_{1}, 5 \mathrm{p} 10 \mathrm{~s}{ }^{3} \mathrm{P}^{\circ}{ }_{1}$, and $5 \mathrm{~s} 5 \mathrm{p}^{33} \mathrm{~S}^{\circ}{ }_{1},{ }^{1} \mathrm{D}^{\circ}{ }_{2}$ odd-parity levels of Sn I, which were measured in the present work, are listed in table 1. The quoted error bars consist of both the statistical uncertainties from different recordings and the systematic errors resulting from the fitting procedure. For some levels in table 1 , the assigned electronic configurations and/or terms differ in the literature due to the strong mixings in the composition of the levels. We have adopted the most credible assignments in the table. In a limited number of cases, several different designations are indicated.

The measured lifetime values are in the range between 4.6 and $292 \mathrm{~ns}$. The lifetimes of the $5 \mathrm{p} 5 \mathrm{~d}^{3} \mathrm{~F}^{\circ}{ }_{2,3}$ and ${ }^{1} \mathrm{D}^{\circ}{ }_{1,2,3}$ levels are in reasonable agreement with the previous data [12, 13, 16-18]. When compared with the experimental results reported by $\mathrm{Xu}$ et al [19] for $5 \mathrm{p} 7 \mathrm{~s}^{3} \mathrm{P}^{\circ}, 5 \mathrm{p} 5 \mathrm{~d}^{1} \mathrm{P}^{\circ}{ }_{1}$, $5 \mathrm{p} 6 \mathrm{~d}^{3} \mathrm{~F}_{2}^{\circ}$ and $5 \mathrm{p} 6 \mathrm{~d}^{3} \mathrm{D}^{\circ}{ }_{1,3}$, it is found that only the lifetime of the $5 \mathrm{p} 5 \mathrm{~d}^{1} \mathrm{P}^{\circ}{ }_{1}$ level is basically consistent with the result obtained in this paper, while the lifetimes of the $5 \mathrm{p} 7 \mathrm{~s}^{3} \mathrm{P}^{\circ}{ }_{1}$ level and the other three $5 \mathrm{p} 6 \mathrm{~d}$ levels are much longer than our results. Considering the discrepancy for the 5p6d levels and the $5 \mathrm{p} 7 \mathrm{~s}^{3} \mathrm{P}^{\circ}{ }_{1}$ level, the following considerations apply. It is well known that the radiative lifetimes of unperturbed Rydberg levels are proportional to $\left(n^{*}\right)^{3}, n^{*}$ being the effective quantum number [21,32]. Based on this relation, the lifetimes of the $5 \mathrm{p} 5 \mathrm{~d}, 5 \mathrm{p} 6 \mathrm{~d}$ and $5 \mathrm{p} 7 \mathrm{~s}$ levels measured in the present experiment could be evaluated from the previous measured lifetimes of some related levels, and they are shown in table 2 . In the case of a perturbation, these evaluated values should be even shorter. Therefore, it can be obviously seen that the $5 \mathrm{p} 7 \mathrm{~s}$ and $5 \mathrm{p} 6 \mathrm{~d}$ lifetimes measured in this paper are expected to be more reliable than those reported by Xu et al [19]. In addition, for the $5 \mathrm{p} 7 \mathrm{~s}^{3} \mathrm{P}^{\circ}{ }_{1}$ level, the risetime of about $50 \mathrm{~ns}$ in the fluorescence curve shown in figure 3 of the paper written by $\mathrm{Xu}$ et al [19] is much longer than the fluorescence risetimes $(15 \sim 20 \mathrm{~ns})$ of all the levels measured in this paper. It is reasonable to assume that the signal emitted by this level was perturbed by the fluorescence light from a lower level. By simulating the fluorescence decay behaviours using the rate equation method, the simulated fluorescence risetimes of the $5 \mathrm{p} 7 \mathrm{~s}^{3} \mathrm{P}^{\circ}{ }_{1}$ and the cascade level are 14.5 and $42.9 \mathrm{~ns}$, respectively, which are in good agreements with our observations and the presentation shown in figure 3 of [19]. Therefore, it is a reasonable assumption that the fluorescence decay curves of the 5p6d levels measured in [19] have also been disturbed by a similar phenomenon.

\section{Conclusions}

The experimental lifetimes of 38 highly lying odd-parity levels in the 5pnd $(n=5-8), 5 \mathrm{p} n \mathrm{~s}(n=7,9$ and 10) and 
$5 \mathrm{~s} 5 \mathrm{p}^{3}$ configurations of $\mathrm{Sn} \mathrm{I}$, in the energy range extending from 43682.737 to $56838.68 \mathrm{~cm}^{-1}$, have been investigated using the time-resolved laser-induced fluorescence technique. The lifetime results obtained in this paper will provide an absolute calibration scale for the experimental (or theoretical) transition probabilities and oscillator strengths of Sn I when the required branching fractions will be available. Most of the lifetimes measured in the present paper are reported for the first time. They are expected to be helpful in many fields of physics including astrophysics and plasma physics. In addition, they provide additional insight into the complex atomic structure and properties of this heavy neutral element which has attracted considerable interest recently, a valuable attempt on the theoretical side being provided e.g. by Oliver and Hibbert [10].

\section{Acknowledgments}

This work was supported by the National Natural Science Foundation of China (contract nos 10574056 and 10974066) and by the Program for New Century Excellent Talents in University (China) (contract no NCET-05-0302). Financial support from the Belgian FRS-FNRS is also acknowledged. PP, PQ and EB are Research Associate, Senior Research Associate and Research Director, respectively, of this organization.

\section{References}

[1] Brown C M, Tilford S G and Ginter M L 1977 J. Opt. Soc. Am. 67607

[2] Moore C E 1958 Atomic Energy Levels vol 3, CNBS No. 467 (Washington, DC: US Govt Printing Office) p 74

[3] Brill W G 1964 PhD Thesis Purdue University, Purdue

[4] Wilson J W 1964 PhD Thesis Imperial College of Science and Technology, London

[5] Nadeem A, Ahad A, Bhatti S A, Ahmad N and Baig M A 1999 J. Phys. B: At. Mol. Opt. Phys. 325669

[6] Nadeem A, Bhatti S A, Ahmad N and Baig M A 2001 J. Phys. B: At. Mol. Opt. Phys. 342407
[7] Nadeem A, Bhatti S A, Ahmad N and Baig M A 2000 J. Phys. B: At. Mol. Opt. Phys. 333729

[8] Jin M, Ding D, Liu H and Pan S 1990 Inst. Phys. Conf. Ser. 114235

[9] Dembczynski J and Rebel H 1984 Physica C 125341

[10] Oliver P and Hibbert A 2008 J. Phys. B: At. Mol. Opt. Phys. 41165003

[11] Sansonetti J E and Martin W C 2005 J. Phys. Chem. Ref. Data 341559

[12] Penkin N P and Slavenas I Y-Y 1963 Opt. Spectrosc. 1583

[13] Lawrence G M 1967 Astrophys. J. 148216

[14] Brieger M and Zimmermann P 1967 Z. Naturforsch. A 222001

[15] Zafra R L and Marshall A 1968 Phys. Rev. 17028

[16] Holmgren L and Svanberg S 1972 Phys. Scr. 5135

[17] Andersen T, Madsen O H and Sørensen G 1972 J. Opt. Soc. Am. $\mathbf{6 2} 1118$

[18] Gorshkov V N and Verolainen Y F 1985 Opt. Spectrosc. 59 1157

[19] Xu J, Feng Y, Sun G and Dai Z 2009 Chin. Phys. B 183828

[20] Zhang Y et al 2008 Phys. Rev. A 78022505

[21] Zhang W et al 2009 Eur. Phys. J. D 551

[22] Adelman S, Bidelman W P and Pyper D 1979 Astrophys. J. Suppl. 40371

[23] Asplund M, Grevesse N and Sauval A J 2005 The solar chemical composition ASP Conf. Series 336: Cosmic Abundances as Records of Stellar Evolution and Nucleosynthesis ed F N Bash and T G Barnes (San Francisco, CA: Astronomical Society of the Pacific) p 25

[24] Pennington J N 1999 Mod. Met. 5538

[25] Dai Z, Zhankui J, Xu H, Zhang Z, Svanberg S, Biémont É, Lefèbvre P-H and Quinet P 2003 J. Phys. B: At. Mol. Opt. Phys. 36479

[26] Berzinsh U, Caiyan L, Zern R, Svanberg S and Biémont É 1996 Phys. Rev. A 551836

[27] Lawler J E, Bonvallet G and Sneden C 2001 Astrophys. J. 556452

[28] Zhang Z, Svanberg S, Quinet P, Palmeri P and Biémont É 2001 Phys. Rev. Lett. 87273001

[29] Den Hartog E A, Herd M T, Lawler J E, Sneden C, Cowan J J and Beers T C 2005 Astrophys. J. 619639

[30] Theodosiou C E 1984 Phys. Rev. A 302881

[31] Mayo R, Campos J, Ortiz M, Xu H, Svanberg S, Malcheva G and Blagoev K 2006 Eur. Phys. J. D 40169

[32] Aymar M, Grafström P, Levinson C, Lundberg H and Svanberg S 1982 J. Phys. B: At. Mol. Phys. 15877 